\title{
Learners' pronunciations of familiar and unfamiliar French words: what can they tell us about phonological decoding in an L2?
}

\author{
Robert Woore, University of Oxford Department of Education
}

\section{Acknowledgments}

I am very grateful to the school students who took part in this research and to the teachers who facilitated it. In particular, I could not have managed without the support and encouragement of the Head of Department in the participating school. I would also like to thank Professor Ernesto Macaro for his valuable comments on an earlier draft of this article, and to Laura Molway for assisting with interrating.

\begin{abstract}
Phonological decoding, defined here as converting the written forms of words (or letter strings) into the phonological forms they represent, has been argued to play an important role in various aspects of L2 learning. Previous studies have emphasized the importance of transfer in L2 decoding, interpretable as the automatic triggering of L1-based symbol-sound correspondences by $L 2$ written input. However, in the case of familiar words, it may be possible for learners to retrieve pre-stored phonological representations based on the recognition of the words as graphic wholes, and thus to pronounce them correctly despite a lack of knowledge of symbol-sound correspondences at a sub-lexical level. To explore these issues, 31 below-intermediate learners of French in an English secondary school completed (a) a Reading Aloud Test, to assess their accuracy of decoding familiar and unfamiliar French words; (b) a scaffolded Picture Naming Task, to elicit their stored phonological pronunciations of the same familiar words; and (c) a vocabulary questionnaire, to assess their knowledge of the items included in the preceding two tests. Participants' decoding in the Reading Aloud Test was more accurate for familiar than unfamiliar words, though still inaccurate in a majority of cases. Their pronunciations of the same familiar words on the Reading Aloud Test and Picture Naming Task sometimes differed. Further, their pronunciations of familiar items on the Picture Naming Task themselves showed some influence of English symbol-sound correspondences, despite the absence of written stimuli. Theoretical and pedagogical implications of these findings are discussed.
\end{abstract}

\section{Introduction}

Phonological decoding may be defined as converting the written forms of words (or letter strings) into the phonological forms they represent. The resulting phonological forms may be vocalized (e.g. when reading aloud) or may remain within the reader's 'inner voice'. This definition is deliberately broad, encompassing the decoding of both (a) words which the reader already knows orally, whose phonological representations are stored in her/his mental lexicon; and (b) unfamiliar words and pseudowords, for which phonological forms must be generated at point of naming, using knowledge of the language's symbol-sound correspondences at a sub-lexical level.

Decoding is often studied as a subskill of reading. However, there is evidence to suggest that being able to decode accurately and efficiently in an $L 2$ underpins various other aspects of language learning, including vocabulary acquisition (Hamada \& Koda, 2008, 2010; Woore, 2013), writing (Macaro, 2007) and motivation (Erler, 2003; Erler and Macaro, 2011). There is thus a clear imperative for $L 2$ educators to understand the processes involved in $L 2$ decoding, the development thereof and how this can best be promoted in the classroom.

Equally, studies of $L 2$ decoding contribute to understanding the processing of $L 2$ writing systems more broadly. Much work in this area has focussed on learners of English, often highly proficient 
and residing in Anglophone countries (Hamada and Koda, 2008). By contrast, the current study investigates English-speaking learners of French with relatively low L2 proficiency, based in classrooms with severely limited linguistic input.

A consistent theme in previous $L 2$ writing system research has been the idea that (a) readers develop particular mechanisms for processing written text in their L1, shaped by the characteristics of that language's writing system; and (b) these mechanisms are then 'transferred' to processing written text in the L2 (e.g. Brown \& Haynes, 1985; Akamatsu, 1999; Koda, 1989, 1990, 1999; Muljani, Koda \& Moates, 1998). Thus, for example, Koda (1999:53) claims that, when reading in L2 English, readers with an alphabetic L1 writing system such as Korean "rely heavily on intraword analysis in obtaining a word's phonology", whereas readers of a morphemic L1 such as Chinese are more likely to "retrieve phonological information lexically through whole-word (or morpheme) activation".

Such L1-to-L2 transfer has been interpreted within a connectionist perspective as the automatic (and therefore non-volitional) activation of L1-tuned processing mechanisms upon exposure to L2 written input (Koda, 2007). Its effects will sometimes be facilitative, where the L1 and L2 writing systems overlap, and sometimes adverse, where the systems differ. On this basis, Koda (2005) proposed the "Orthographic Distance Effect", whereby the ease with which L2 decoding proficiency develops is positively related to the degree of similarity ('congruence') between the L1 and L2 writing systems. In the case of highly congruent pairs of writing systems, L2 decoding proficiency is hypothesized to develop more quickly, because relatively little 'retuning' of the existing L1-based system is needed.

However, even learning to decode a congruent $L 2$ writing system is not necessarily simple. Numerous studies based in Modern Foreign Language (MFL) classrooms in English secondary schools have found that learners have low proficiency in French decoding and make little progress in this area, even over several years - at least in the absence of explicit decoding instruction (Erler, 2003; Woore, 2009, 2010, 2011, 2014a; Erler and Macaro 2011). This is despite the fact that French and English are highly congruent writing systems which both use the Roman alphabet. Participants in the above studies have been found to rely on what Erler (2003:169) calls the "heuristic of English": that is, they consistently pronounced French words according to English symbol-sound correspondences (e.g. 'loquet' (/loke/, 'door catch') as /lpkwet/).

Why might this be? One factor may be the unfavourable climate facing L2 learners in English MFL classrooms - a climate characterized by "highly challenging systemic pressures" (Pachler, 2002:6) such as hostile attitudes to foreign languages in wider society, low student motivation (Coleman et al., 2007) and limited teaching time (typically two to three hours per week). However, this is unlikely to be the whole story. Recent studies investigating learners in a range of other socio-educational contexts, where the L1 and L2 also both use the Roman alphabet (e.g. Italian-English; EnglishGerman), are relevant here. These studies, too, have noted a persistent influence of $L 1$ symbolsound correspondences on the pronunciation of $L 2$ words. This has occurred even where the participants have had many years of formal instruction in the L2 (Bassetti and Atkinson, 2015), have received massive amounts of L2 input (Young-Scholten and Langer, 2015) or are highly proficient bilinguals living in the target country (Piske et al., 2002). Therefore, a possible alternative explanation is that English learners' problems with French decoding derive at least partly from the very fact that the L1 and L2 writing systems are so similar (Woore, 2011, 2014a). Rather than being simply facilitative, the familiar alphabet may make the automatic triggering of L1-entrenched symbol-sound correspondences more likely, even where these are incorrect.

Suppression of such incorrect, L1-based connections is therefore crucial in L2 decoding. However, this is only a first step: learners must also know the appropriate L2 symbol-sound correspondences to put in their place - knowledge which the MFL learners in previous studies have apparently lacked. 
This problem is exemplified by Woore's $(2010,2011)$ self-report studies, in which near-beginner learners of French attempted to decoded unfamiliar L2 words. Participants frequently felt that the English-based pronunciations they had produced were incorrect and they wanted to make their pronunciations sound 'more French'. However, "beyond this basic awareness of difference, participants lacked specific knowledge about what the French pronunciations of words should be" (Woore, 2010:15).

Many of the previous studies in the English MFL context cited above (including all those by Woore) have focussed on the decoding of unfamiliar words. Since learners do not know these words orally, the only way to decode them is by engaging in intraword analysis and using symbol-sound correspondences at a sub-lexical level. By contrast, when decoding familiar words, L2 readers may retrieve pronunciations already stored in long-term memory. Effectively, such words would be treated like 'exception' words in L1 English: that is, words whose pronunciations do not follow regular grapheme-phoneme correspondences (e.g. 'have', pronounced/hav/, and not/heIv/ as in 'wave', 'save', 'brave', etc.). The mechanisms by which such exception words are decoded remain contested in the word recognition literature, particularly in terms of the debate between so-called 'dual route' models on the one hand and connectionist models on the other (see Coltheart, 2005 and Plaut, 2005 for overviews of these two positions respectively). This debate notwithstanding, for our purposes the essential point remains that $\mathrm{L} 2$ learners may be able to access stored pronunciations of familiar words when they see them in written form, and thus override any L1based symbol-sound correspondences which may have been activated automatically. For example, learners who have secure oral knowledge of the French words 'vert' (/vعs/, 'green') and 'chat' (/Ja/, 'cat') - and who are able to link these pronunciations successfully to their written forms - may avoid pronouncing them as /və:t/ or /tfat/, according to English symbol-sound correspondences. They may thus be able to decode the words correctly, even though they do not know the individual symbol-sound correspondences that make up these words in French.

There are, however, potential problems with a 'whole word' approach to decoding. First, learners' stored pronunciations of familiar words may themselves be incorrect. In particular, given the relatively large proportion of written (as opposed to spoken) L2 input in classroom settings, there is a risk of learners internalizing what Bassetti (2008) calls "orthography-induced pronunciations": that is, pronunciations arising from decoding the written forms incorrectly, under the influence of L1 symbol-sound correspondences (e.g. 'chat', /Ja/, 'cat' being pronounced like the English homograph 'chat', /t fat/). These orthography-induced pronunciations may then become entrenched. For example, participants in Young-Scholten and Langer's (2015) study, mentioned above, pronounced words in ways which reflected L1 (English)-based decoding of orthographic forms, even though the data was collected by means of spontaneous conversation and oral elicitation tasks - i.e. involving no written cues. Second, even where learners do hold correct pronunciations of familiar words in long-term memory, automatically-triggered L1 symbol-sound correspondences may nonetheless surface when the words are decoded, if these are not successfully suppressed.

Based on the issues raised above, the current study addresses the following research questions:

1. How accurately do participants decode (a) familiar and (b) unfamiliar written French words?

2. How can participants' decoding of these items be categorized?

3. How accurately do participants pronounce the same familiar French words when retrieving their pronunciations from memory, without access to the written forms?

4. How can participants' retrieved pronunciations of these items be categorized?

Of particular interest are the following issues: 
(a) whether participants pronounce familiar words more accurately than unfamiliar ones, which may suggest that different decoding mechanisms are involved for these two categories of words;

(b) whether participants pronounce the same familiar words differently when decoding their written forms and when retrieving the words from memory with no written stimulus;

(c) whether participants make similar or contrasting errors when pronouncing familiar and unfamiliar words in the two conditions (decoding versus retrieving from memory), which may shed light on the decoding mechanisms involved.

\section{Method}

\section{Sample}

This study was conducted in a state-funded, non-selective secondary school, located in a large town in South-East England. Statistics published by the UK Department of Education show that the school is around the national average in terms of students' attainment in national examinations; however, it has below average numbers of students who are eligible for Free School Meals (a widely-used proxy for low socio-economic status); who have documented Special Educational Needs; and whose first language is known or believed to be other than English ${ }^{1}$. Nonetheless, the school is arguably not untypical of many other state secondary schools in non-inner city areas.

38 students in their fourth year of secondary education (age 15-16) were learning French in this school, divided into two classes. Each had a different French teacher. In contrast to participants in the previous decoding studies based in MFL classrooms mentioned above, they had chosen to continue learning a foreign language beyond age 14, when it becomes optional. They were thus working towards their national GCSE examination (General Certificate in Secondary Education) in French. This roughly equates to CEFR level A2 at the higher grades. In subsequent practice examinations, completed the following academic year, participants' grades ranged from $A^{*}$ to $D$, with the median being $B$. (Pass grades run from $A^{*}$ to $G$ ).

All of these 38 students were invited to take part. Voluntary informed consent was sought from both students and parents on an opt-out basis. 32 students ( 17 male, 15 female) agreed to participate and were present for data collection. One participant's data was subsequently excluded at the analysis stage, because (a) her home language, as indicated in a background questionnaire, was Portuguese, which is closely related to French; and (b) her attainment in English, as shown by the school's academic records, was considerably below that of other participants. Four other students reported speaking languages other than English at home; however, their home languages were not closely related to French and they had similar levels of attainment in English to their English-L1 classmates. They were therefore included in the analysis. School data further showed that two other participants were eligible for free school meals. None had documented special educational needs.

\section{Instruments}

A Reading Aloud Test (RAT) was developed for the current study. It comprised 18 words presumed to be familiar to participants and 18 presumed unfamiliar, based on an analysis of students' schemes of work and conversations with their teachers. To ensure that the words in these two categories were comparable in terms of decoding difficulty, each familiar word was paired with an unfamiliar word

\footnotetext{
${ }^{1}$ This information is available on line at www.gov.uk/government/statistics. However, the specific link for information relating to the sample school is withheld, to maintain confidentiality.
} 
having the same spelling body and differing only in respect of their initial consonant(s): e.g. familiar 'chaise' (/Jعz/, 'chair') - unfamiliar 'glaise' (/glez/, 'clay'). At the analysis stage, the initial consonants were then discarded, so that only the pronunciations of the two identical spelling bodies were compared.

The RAT also included 14 other French words and phrases, presumed to be highly familiar to participants (e.g. 'Bonjour', 'J'adore'). These were intended partly as distractors, to prevent participants noticing that numerous test items had identical spelling bodies; and partly to prevent them feeling discouraged by having to read aloud so many unfamiliar French words. The total number of items in the test was therefore 50. Additionally, participants saw ten practice items before the test began. The full list of RAT items appears in Appendix 1. (In order to address additional research questions not included in the current paper, half the RAT items were also interlingual homographs of English words. These were evenly distributed between the familiar and unfamiliar words. Analysis showed that there were no differences in the accuracy with which participants decoded the homographs and non-homographs, in either the familiar or unfamiliar categories).

To check whether participants did indeed know those RAT items which were presumed to be familiar, a vocabulary questionnaire was created, loosely based on Paribakht and Wesche's (1996) Vocabulary Knowledge Scale. This included all the RAT items. For each item, participants were asked to select one of four options:

(a) Yes, I know this word. I can remember what it means. It means

(b) I am not sure, but I think I can remember what it means. I think it means

(c) I'm not sure, but I think I can guess / work out the meaning. I think it means

(d) No, I don't know what this word means.

Option (c) was designed to distinguish between stored vocabulary knowledge on the one hand, and the results of strategic behaviour (such as guessing at meanings) on the other. The latter might be particularly encouraged by the high number of interlingual homographs. For example, participants might correctly guess that the French word 'stable' means the same as the English word 'stable', even though they had never seen the word before, in which case it could not be described as 'familiar' to them. The vocabulary questionnaire was completed by all but one participant, who was absent on the day of administration.

Finally, participants completed a scaffolded Picture Naming Task (PNT), designed to elicit their stored pronunciations of familiar words in the absence of written stimuli. For each of the words in the 'presumed familiar' category, a picture prompt was created, together with a gapped sentence intended to help participants recall the word (the 'scaffolding'). The target item was omitted from this sentence, but its initial letters were provided. (Recall that these initial letters were in any case not included in the analysis). Participants therefore had to recall only the word's phonological rime, which was the object of analysis. For example, for the word 'chat', a picture of a cat was used, together with the following sentence:

As-tu an animal? Oui, j'ai un ch

Translation (not included in the test): 'Do you have a pet? Yes, l've got a c_

\section{Procedure}

The RAT was administered individually by the researcher during participants' French lessons in a quiet, private location in school. Instructions were presented in English using a standard text displayed on computer screen and read aloud by the researcher, with time afterwards for participants to ask questions. It was emphasized that the words were all in French, that some were 
likely to be unfamiliar but that participants should attempt to read them aloud nonetheless. A summary of the instructions were then repeated orally in French, to help get participants in a 'French frame of mind' and thus discourage them from decoding the words using English symbolsound correspondences. Participants first completed the practice items before progressing to the main test. They began this when ready and proceeded through it at their own pace. The order of the items was random and different for each participant. For each item, a fixation mark (+) first appeared on the screen accompanied by a short beep. 500 milliseconds later, the fixation mark was replaced by the target item. Participants read this word aloud when ready and pressed the space bar to advance to the next item. The test was audio-recorded.

Subsequently, participants completed the PNT. Ideally, this would have been done on a different day, but this was not possible for logistical reasons. Instead, a gap of a few minutes was left, in which the researcher completed administrative tasks and had a brief conversation about learning French with the participant. This was to prevent phonological forms being held in working memory between the RAT and PNT sessions. Instructions for the PNT were then given and practice items completed, before proceeding to the main test. For each item, participants were shown the picture and a written representation of the prompt sentence, which was also read aloud by the researcher. Participants had as long as they wished in order to produce the target word, although if they seemed uncomfortable, the researcher reassured them (in French and English) that this was not a cause for concern and moved them on to the next item. Participants were also given the option of saying 'Je ne sais pas' / 'I don't know' in either language if they wished to skip an item. Again, the test was audio-recorded.

Finally, participants completed the vocabulary knowledge questionnaire under supervision of their teacher, who first delivered the test instructions using a script prepared by the researcher and allowed time for questions. The teacher also ensured that students completed the questionnaire individually, without conferring with peers.

\section{Analysis}

A 'broad' (phonemic) transcription of participants' RAT and PNT outputs were prepared by the researcher, a trained phonetician, using the phonetic alphabet of the International Phonetic Association (IPA, 2005). These transcribed pronunciations were then coded as follows:

(a) correct French pronunciation: e.g. <faux $>$ ('false') pronounced /fo/;

(b) 'acceptable' French pronunciation, containing the correct French phonemes, but realized with some degree of foreign accent: e.g. <faux > pronounced /fəv/ and <lait> pronounced $/ \mathrm{l} \varepsilon \mathrm{I} /$, where the vowels can be interpreted as anglicized realizations of the French phonemes /o/ and /e/ respectively;

(c) English-based pronunciation, entirely consistent with English symbol-sound

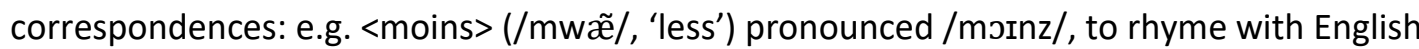
'coins';

(d) mixed pronunciations, reflecting partly French and partly English symbol-sound correspondences: e.g. <moins> pronounced/morn/, with the vowel being consistent with English symbol-sound correspondences but the final consonant grapheme having no phonological realization, as in French;

(e) pronunciations containing 'idiosyncratic' realizations of one of more graphemes, which would not be permissible in this context according to either French or English symbol-sound correspondences: e.g. $<$ maux $>$ (/mo/, 'pains') pronounced /mjeks/;

(f) whole word errors, in which the target word is pronounced like a different but orthographically similar word: e.g. <France $>$ (/fьñs/, 'France') pronounced /f.ũ̃seI/, as if it were the word <français> ('French'). 
These coding categories were not predetermined and imposed on the data; rather, on reading and re-reading the transcriptions, they seemed to the researcher to emerge from the data and to characterize it effectively. The second transcriber subsequently reviewed the codes and agreed with them. A set of 'interrater' transcriptions (see below) was also coded using the same categories.

Finally, the codes resulting from this analysis were used to derive a score for each item, based on the phonological rimes only. One point was given for correct or 'acceptable' pronunciations (categories (a) and (b)) and no points for incorrect pronunciations (categories (c) to (f)). The reason for awarding one point for 'acceptable' pronunciations was to allow for foreign accent, the focus being the accuracy of participants' decoding, not of their French pronunciation per se.

A $25 \%$ subsample of recordings were transcribed again by a second transcriber, who had received training in the International Phonetic Alphabet. The second transcriptions matched the original ones for $88.9 \%$ of items in the interrating sample. The second transcriptions were then assigned category codes and scores as described above. The codes and scores derived from the second transcriptions matched those based on the original transcriptions in $94.1 \%$ and $97.9 \%$ of cases respectively. Thus the coding and scoring of the data, which forms the basis for the analysis reported in this article, can be considered highly reliable.

\section{Findings}

\section{How accurately do participants decode (a) familiar and (b) unfamiliar written French words?}

As a first step towards addressing Research Question 1, participants' responses on the vocabulary questionnaire were analysed. This was to establish which words were genuinely familiar and unfamiliar to participants, rather than simply being presumed so. A word was counted as 'familiar' to a participant if $\mathrm{s} / \mathrm{he}$ both (a) reported that $\mathrm{s} / \mathrm{he}$ knew it or thought $\mathrm{s} / \mathrm{h}$ could remember it, and (b) supplied an acceptable translation of it. Conversely, a word was deemed unfamiliar to a participant if $s / h e$ either (a) said that $s /$ he did not know it or thought that $s /$ he could guess its meaning, and/or (b) supplied an incorrect translation, irrespective of which of the four response options was chosen.

The mean number of test items that participants knew was $15.4(S D=1.9)$. Of the eighteen 'presumed familiar' words, fourteen were indeed known by all or almost all respondents. By contrast, 'date' ('date') was known by a somewhat smaller number ( $\mathrm{N}=22)$; and three were known by only three or four participants each ('vent', 'wind'; 'voile', 'sail'; 'chaise', 'chair'). Of the eighteen 'presumed unfamiliar' words, fourteen were indeed unknown by any participants. One word ('fart', 'ski wax') was known by two participants, and two others ('stable', 'stable'; 'grain', 'grain') were known by seven participants.

For each participant, an individualized set of matched word pairs with identical spelling bodies was established (e.g. 'chaise'/'glaise'), where one member of each pair was known by that participant and the other unknown, as determined by her/his vocabulary questionnaire responses. This therefore gave an equal number of known (familiar) and unknown (unfamiliar) items for each participant, with the spelling bodies being identical across the two sets of items. The total number of orthographically matched pairs of familiar/unfamiliar words was 428 , with a mean of 13.8 per participant.

Within the set of matched pairs of items available for each participant, the mean number of spelling bodies in familiar words which were decoded accurately - that is, pronounced either correctly or 
'acceptably' - was 5.7 (SD=3.6). For unfamiliar words, the figure was 4.6 ( $\mathrm{SD}=3.5)$. Overall, participants decoded $41.6 \%$ of spelling bodies accurately in familiar words, compared to $33.2 \%$ in unfamiliar words. A paired samples t-test found a significant difference between the numbers of spelling bodies decoded accurately in familiar versus unfamiliar words, $\mathrm{t}(30)=4.289, p$ (twotailed) $=<.001, d=0.33^{2}$.

\section{How can participants' decoding of familiar and unfamiliar words be categorized?}

To provide further insight into participants' decoding of the RAT items, the percentage of pronunciations falling into each of the coding categories described earlier was calculated, based on the same set of 428 orthographically matched pairs of familiar and unfamiliar words as described above (Table 1).

\section{[TABLE 1 ABOUT HERE]}

A chi square test found no significant differences between participants' realizations of familiar versus unfamiliar words, based on the categories in Table 1; however, the $p$ value approached significance, $\chi(5)=10.006, p=.075$. At a descriptive level, some patterns appear to emerge. First, familiar words are associated with higher numbers of both correct and acceptable pronunciations (hence the significant difference in accuracy noted in answer to Research Question 1 above). Conversely, more pronunciations are entirely consistent with English symbol-sound correspondences amongst the unfamiliar words ( $25.7 \%$ of realizations) than amongst the familiar ones $(20.1 \%)$. Typical examples in this category are pronunciations of 'chat', 'voile', 'sert' and 'grain' as, respectively, /tfat/, /vorl/, /sə:t/ and /gıeIn/ (i.e. rhyming with English 'hat', 'spoil', 'Bert' and 'gain'). By contrast, the number of 'mixed' pronunciations (those reflecting some aspects of both French and English symbol-sound correspondences) appear relatively similar across the two groups of words, albeit slightly higher for unfamiliar than familiar words $(15.2 \%$ versus $14.7 \%$ of pronunciations respectively).

At an individual level, several participants reflected the general pattern described above: that is, in the familiar condition, they produced a correct or 'acceptable' pronunciation of a given spelling body; but in the unfamiliar condition, their pronunciation of that same spelling body was unacceptable, being consistent with English symbol-sound correspondences. For example, one participant pronounced the familiar word <pain> (/pæ̃/) acceptably as/pan/, but its unfamiliar counterpart <grain $>$ (/gвæ̃ /) as /gıєIn/. Another pronounced the familiar word <chat> correctly as $/ \mathrm{Ja} /$ but the unfamiliar $<$ fat $>$ as $/$ fat $/$.

Additionally, there were (again at a descriptive level) more 'idiosyncratic' pronunciations amongst the unfamiliar items (25.2\%) than the familiar items (22.0\%). Pronunciations in this category were varied in nature. However, several could be interpreted as the result of overgeneralizing L2 phonological patterns or symbol-sound correspondences. For example, word-final $<\mathrm{e}\rangle$ (which has no phonological realization in French) was often pronounced as if it had an acute accent (<é>), giving pronunciations such as /vwaleI/ for 'voile' (/vwal/, 'sailing') and /JaseI/ for 'chaise' (/Jعz/, 'chair'). In several other cases, the 'silent final consonant' rule (whereby many word-final consonants are not phonologically realized in French) appears to have been wrongly applied to consonants followed by word-final <e>, as in 'rate' (/вat/, '[s/he] misses'), pronounced/גعI/ and 'frites' (/fuit/, 'chips'),

\footnotetext{
${ }^{2}$ Visual inspection of histograms suggested non-Normal distributions for both groups. Non-parametric tests were therefore also conducted. A Wilcoxon signed ranks test obtained similar findings to the t-test: a significant difference was found between the percentages of familiar words ( $M d n=5)$ and unfamiliar words $(\mathrm{Mdn}=4)$ which were decoded accurately, $Z=3.355, p=.001$.
} 
pronounced /f.ii:/. Other pronunciations, however, defied any obvious explanation, as in the realizations of the vowels in 'maux' as/mjeks/, 'choix' as/Jys/ and 'glaise' as/glas/.

Finally, there were around twice as many 'whole word errors' amongst the familiar than the unfamiliar words. However, the numbers involved are very small and mainly resulted from mispronunciations of two particular items: 'France' ('France'), read by six participants as 'français' ('French'); and 'voile' ('sailing'), read by three participants as 'violet' ('purple').

\section{How accurately do participants pronounce the same familiar words when retrieving their pronunciations from memory, without access to the written forms?}

In the scaffolded PNT, the number of items for which participants produced an oral response (whether correct or incorrect) ranged from 11 to 18, with the mean being 15.3 (SD=1.9). In other words, on average they did not attempt to produce any pronunciation for almost three of the 18 words which they had covered in their French curriculum. The items which participants most often failed to attempt corresponded to those which they reported not knowing on the vocabulary questionnaire: 'voile' ( $\mathrm{N}=23$ null responses in the PNT), 'vent' $(\mathrm{N}=18)$, 'date' $(\mathrm{N}=15)$ and 'chaise' $(\mathrm{N}=11)$. When these four items were excluded from the analysis, leaving 14 words for which all or almost all participants (mean $\mathrm{N}=30.5$ ) produced a phonological form, the mean number of accurate (correct or acceptable) pronunciations was $6.3(\mathrm{SD}=3.1)$. In other words, $45.0 \%$ of the pronunciations produced in response to the PNT were accurate.

Again, for each participant, an individualized set of matched pairs of pronunciations was established. Each pair comprised the decoded version of a given word (produced on the RAT) and the elicited pronunciation of the same word (produced on the PNT). There was therefore an equal number of elicited and decoded pronunciations for each participant, with the target words being identical across the two sets of pronunciations. Words which the participant did not know (as revealed by the vocabulary questionnaire) were also excluded from these individualized sets of matched pronunciations. This is because the aim was to investigate the possibility that participants sometimes decoded familiar items by retrieving their pronunciations from long-term memory; this would clearly only be possible insofar as the participant knew the word and had an existing phonological representation of it in memory.

Across all participants, the total number of matched pairs of pronunciations (elicited / decoded) of familiar words was 424 , with a mean of 13.7 per participant. Overall, participants pronounced $48.4 \%$ of spelling bodies accurately in the elicitation condition and $45.1 \%$ in the decoding condition. A paired samples t-test found no significant difference between the numbers of items pronounced accurately in the elicitation versus the decoding condition, $\mathrm{t}(30)=1.627, p$ (two-tailed) $=.114^{3}$.

\section{How can participants' retrieved pronunciations of these items be categorized?}

Using the same set of 424 matched pairs of pronunciations described above, participants' two pronunciations of each familiar word - (a) the decoded pronunciation produced on the RAT and (b) the retrieved pronunciation produced on the PNT - were compared, again focussing on phonological rimes only: that is, initial consonants were ignored. The percentage of words for which participants' two pronunciations of the word's phonological rime were identical in the two tasks ranged from 42.9

\footnotetext{
${ }^{3}$ Again, a Wilcoxon signed ranks test was additionally conducted due to non-Normal distributions of the data. This obtained similar findings to the t-test: no significant difference was found between the numbers of familiar words pronounced accurately in the elicitation condition ( $M d n=7)$ and in the decoding condition (Mdn=6), Z=1.620, $p=.105$.
} 
to 92.9 , with a mean value of $63.6(\mathrm{SD}=13.6)$. Thus, on average participants' two pronunciations of the same word differed in almost one third of cases.

In order to gain further insight into participants' elicited pronunciations of the familiar items as produced in the PNT, the transcriptions of the phonological forms they produced were classified using the coding scheme described above. The results of this analysis - again based on the 424 matched pairs of decoded and elicited pronunciations of the same familiar words - appears in Table 2. The figures for the decoded pronunciations within these pairs (as produced in the RAT) are also given for comparison.

\section{[TABLE 2 ABOUT HERE - PLEASE NOTE TABLE 2 INCLUDES A FOOTNOTE]}

A chi square test found that participants' pronunciations of the same familiar words differed significantly between the PNT and the RAT, $\chi(5)=23.121, p<.001$. No cells had expected counts below 5 . The standardized residuals were greater than \pm 1.96 in respect of whole word errors, indicating that these occurred significantly more often on the PNT $(p<.05)$. Examples of such errors include participants saying 'quatre' ('four') or 'quinze' ('fifteen') instead of 'quart' ('quarter'); 'légume' ('vegetable') instead of 'lait' (milk); 'midi' ('midday') instead of 'moins [le quart]' ('[quarter] to'); and, once again, 'français' ('French') instead of 'France' ('France'). The fact that the onset consonants are correct in each case is explained by the fact that these were supplied as part of the carrier sentence (e.g. 'J'aime boire du ', 'I like drinking $\mathrm{m}$ ').

The standardized residual for English pronunciations (1.7) also approached the level associated with statistical significance, reflecting the fact that these accounted for $11.3 \%$ of pronunciations on the PNT compared to $17.5 \%$ on the RAT. Examples of such pronunciations include /fat/ for 'chat' $(/ \mathrm{Ja} /$, 'cat'), /kwo:t/ for 'quart' (/kas/, 'quarter') and /terbəl/ for 'table' (/tablə/, 'table).

Conversely, as reflected in the analysis of accurate pronunciations described above, the combined percentage of correct or acceptable pronunciations was broadly similar across the two tests, albeit (at a descriptive level) slightly higher for the PNT (48.4\%) than the RAT (45.1\%).

\section{Discussion}

\section{Decoding of familiar and unfamiliar words}

In the RAT, participants were found to decode spelling bodies significantly more accurately in familiar words (mean 41.6\%) than unfamiliar words (mean 33.2\%). This was despite the spelling bodies being identical across the two groups of words (familiar/unfamiliar), thus strictly controlling for any confounding variables related to orthographic forms (e.g. the fact that certain letter combinations might be easier to pronounce than others). In a 'deep' orthography such as English, where a given spelling body may be decoded differently according to its context (e.g. <ough> in through, though, trough, tough), this accuracy advantage for familiar words would be expected. In French, however, sub-lexical symbol-sound correspondences are much more consistent, at least when moving from orthography to phonology (Lange and Content, 1999). Thus, in the current study, the orthographically identical spelling bodies in the matched pairs of words (e.g. 'vent' / 'sent') should also be pronounced identically.

What might account for participants' differing pronunciations of the same letter strings in familiar and unfamiliar words? A plausible hypothesis is that, when decoding familiar words, participants were at least sometimes able to retrieve accurate, pre-stored phonological representations of them as wholes from long-term memory, based on pronunciations that they had heard from their teacher 
or other spoken source. This is interesting, since previous L2 writing system research has suggested that, in an alphabetic $L 2$, the whole word recognition mechanism is typically used by learners with morphemic L1 writing systems, such as Chinese, rather than those with an alphabetic L1 (e.g. Koda, 1999). For the participants in the current study, such 'whole word' retrieval may have acted as a compensatory mechanism, allowing them to decode some familiar words correctly despite their lack of decoding proficiency at a sub-lexical level (see below). However, it is not an effective long-term solution: developing their knowledge of French grapheme-phoneme correspondences will ultimately be more efficient, given that these are generally consistent and thus provide a reliable basis for decoding. There is no need for learners to memorize individually the orthographic forms of whole words, which imposes an unnecessary burden on their memory.

Turning to participants' decoding of unfamiliar words in the RAT, here they would need to 'assemble' pronunciations using sub-lexical symbol-sound correspondences in order to pronounce the words accurately. However, as in previous decoding studies based in MFL classrooms (e.g. Woore, 2009, 2011), participants appeared to have low proficiency in sub-lexical decoding, resulting in incorrect pronunciations in over two thirds of cases. As argued in the introduction, this may have various negative consequences for their wider L2 learning.

The hypothesis that participants sometimes used different mechanisms to pronounce the familiar and unfamiliar items in the RAT is supported by the more detailed categorization of their pronunciations. First, at least in descriptive terms, pronunciations which reflected English symbolsound correspondences were more frequent amongst unfamiliar words (around 26\%) than familiar words (around 20\%). This is consistent with the view that, lacking sufficient knowledge of L2 symbol-sound correspondences, participants fell back on "the heuristic of English" (Erler, 2003:169), as has been found in previous studies with this population (Erler, 2003; Woore, 2009, 2010, 2014a). Second (again on a descriptive level), there was a higher proportion of 'idiosyncratic' pronunciations amongst unfamiliar words (25.2\%) than familiar words (22.0\%). These were pronunciations in which the realization of at least one grapheme was incompatible with either French or English symbolsound correspondences, such as 'maux' being pronounced/mjeks/. There are resonances here of Woore's $(2010,2011)$ self-report studies, in which participants knew that the target words should sound 'different to English', yet did not know what the French pronunciations should be. They therefore tried (in vain) to make their pronunciations sound 'more French' by experimenting with various unpredictable sounds.

Finally, returning to participants' pronunciations of familiar words, it is noteworthy that these were incorrect in around $60 \%$ of cases. In other words, despite reporting that they knew a word and being able to translate it successfully, participants were often unable to decode it accurately. Further, although the proportion of 'English' pronunciations was lower for familiar words than for unfamiliar ones in the RAT, nonetheless around one fifth of familiar words were pronounced in ways entirely consistent with English symbol-sound correspondences. One possible explanation for this is that L2 written forms automatically triggered L1 symbol-sound correspondences (Koda, 2007), which then overrode any retrieved pronunciations of the words. Alternatively, it may be that the pronunciations of the familiar words retrieved from long-term memory had been stored incorrectly in the first place. Research questions 3 and 4 were designed to investigate this latter possibility.

\section{Retrieved pronunciations of familiar words}

There was no significant difference between the number of accurate pronunciations in the RAT (decoding condition) and PNT (elicitation condition). At first sight, this appears to support the hypothesis that participants decoded familiar words on the RAT by retrieving their pre-stored pronunciations: where these stored pronunciations were correct (as revealed by the PNT), the 
decoded pronunciations were also correct, and vice versa. However, a comparison of participants' pronunciations of the same words in the PNT and RAT, again using phonological rimes as the unit of analysis, suggests a more complex picture. On average, the elicited and decoded pronunciations of the same words matched each other in only around two thirds of cases. The above hypothesis (that familiar words were decoded by retrieving their pre-stored pronunciations) is thus only partially supported. Other decoding processes also appear to have been at work, at least for some participants and for some familiar words. There was also much individual variation. The percentage of words where the elicited and decoded pronunciations matched ranged from $42.9 \%$ to $92.9 \%$. The factors underlying this variation merit further exploration.

The more detailed categorization of participants' pronunciations showed that, in descriptive terms, correct forms were produced more often in the elicitation condition (35.8\%) than the decoding condition (31.8\%). By contrast, 'English' realizations (those consistent with L1 symbol-sound correspondences) were produced more often in the decoding condition (17.5\%) than the elicitation condition (11.3\%). These findings are consistent with the view that, even when participants held correct phonological representations of familiar words in long-term memory, these were sometimes overridden by L1 symbol-sound correspondences, triggered automatically by the written forms.

In such cases, what the data does not show is whether the participant recognized the word that $s /$ he had decoded incorrectly. For example, imagine that a participant 'knows' the French word 'chat' (/Ja/, 'cat'), in the sense that s/he holds correct and interlinked representations of the word's written form, phonological form and meaning in long-term memory. However, on seeing the written form of the word, s/he pronounces it / $\mathrm{t}$ Jat/, as in the English word 'chat'. To what extent does $\mathrm{s} / \mathrm{he}$ consciously link this written form to the French lexical item? An interesting instance of selfcorrection in the RAT data bears upon this issue. One participant began to read aloud the word 'trois' (/tbwa/, 'three') but then suddenly recognized it and amended her pronunciation:

\section{$/$ tı/ oh my god that's three /tıa//tw//twa/}

Although such self-corrections were rare (occurring in just over $3 \%$ of all RAT pronunciations), this example suggests that they may merit further analysis. They may yield insights into the role of metacognition in beginners' $L 2$ decoding.

It is also noteworthy that, while 'English' realizations were (in descriptive terms) less frequent in the elicitation than the decoding condition, they still constituted over $11 \%$ of elicited pronunciations. Further, a similar number of pronunciations (over 13\%) were partially consistent with English symbol-sound correspondences. This may reflect the persistent influence of orthographic forms (and the L1-based decoding thereof) on participants' stored phonological representations of familiar words (Basssetti, 2008). Alternatively, it may be that, in the PNT, it was the written forms of the familiar words which first came to mind (rather than their phonological forms), and that these were then decoded to sound at the point of naming. In either case, there would appear to be a strong pedagogical rationale for helping classroom-based learners to improve their sub-lexical decoding in the $L 2$, particularly as they are likely to receive a considerable proportion of their $L 2$ input in written form (Woore, 2014b).

A possible methodological artefact must be acknowledged here. The PNT followed the RAT after only a short delay. This might have increased the likelihood that pronunciations produced in the decoding condition influenced those produced subsequently in the elicitation condition. For example, participants may have remembered the forms they produced on the RAT and reproduced these in the PNT, in an attempt to be provide consistent pronunciations of the same word. Even if this were the case, however, it would still suggest that participants' stored phonological 
representations of familiar words were unstable and susceptible to interference from L1-based decoding of the written forms.

\section{Conclusions}

Participants decoded a large majority of both familiar and unfamiliar French words inaccurately. This appears to indicate low $L 2$ decoding proficiency and is consistent with previous findings in the MFL context, even though participants in the current study had been learning the language for longer and had chosen to continue with it beyond the compulsory phase.

Nonetheless, participants decoded the spelling bodies of familiar words significantly more accurately than identical spelling bodies in unfamiliar words. This suggests that, at least in some cases, different decoding mechanisms may have been involved: the retrieval of intact stored pronunciations for familiar words; and the use of sub-lexical symbol-sound correspondences to 'assemble' pronunciations for unfamiliar words. A reliance on retrieving stored pronunciations for familiar words may function as a compensatory mechanism for learners who lack knowledge of $L 2$ symbol-sound correspondences at a sub-lexical level. In the longer term, however, this is an inefficient basis for phonological decoding in French, given that the language's grapheme-tophoneme correspondences are relatively consistent.

A pedagogical implication of the above finding is that teachers may gain a misleading impression of learners' $L 2$ decoding proficiency if they over-rely on simple texts comprising mainly familiar words. These will allow learners to place greater reliance on retrieving stored pronunciations as a basis for their decoding. In turn, this may impede the development of their wider decoding proficiency, by circumventing the need for them to engage in intraword analysis and to develop knowledge of sublexical symbol-sound correspondences.

More detailed analysis of participants' pronunciations in the RAT confirmed the importance of transfer in their L2 decoding, as emphasized in much previous literature. Counter to what has sometimes been implied, the high degree of congruence between participants' L1 and L2 writing systems did not mean that such transfer was simply facilitative. Rather, L1-entreched symbol-sound correspondences appeared to hinder participants' decoding of L2 words, both familiar and unfamiliar. However, there were also signs of participants going 'beyond transfer'. For example, some pronunciations reflected a mixture of both English and French symbol-sound correspondences. Others contained sounds which reflected neither French nor English decoding norms. Further research is required into these 'idiosyncratic' pronunciations, which may reflect learners' developing conceptualizations and hypotheses about L2 symbol-sound correspondences, and thus form part of their decoding 'interlanguage'.

The influence of L1 symbol-sound correspondences on participants' pronunciations also extended to the PNT, even though no written stimuli were presented. This hints at the powerful effects that L1entrenched decoding mechanisms may have on the storage and/or retrieval of L2 lexical items in long-term memory. However, further exploration of this issue is needed in view of the methodological limitations of the current study.

Overall, the findings of this study strengthen the argument that the development of $L 2$ decoding proficiency is not something that can simply be left to take care of itself in the early stages of learning a foreign language - even (or perhaps especially) where the writing system in question is closely related to that of the learners' L1. This argument applies at least to limited-input instructed settings, such as the English MFL classrooms in which the current study was based. There have been calls for explicit decoding instruction in such contexts (e.g. Erler, 2004; Woore, 2009). However, the 
extent to which such instruction can succeed, and the emphasis that should be placed on it within an overall L2 programme of language teaching, remain matters for further investigation.

\section{References}

Akamatsu, N. (1999) 'The Effects of First Language Orthographic Features on Word Recognition Processing in English as a Second Language', in Reading and Writing: An Interdisciplinary Journal, 11: 381-403. doi:10.1023/A:1008053520326.

Bassetti, B. (2008) 'Orthographic input and second language phonology'. In T. Piske and M. Young Scholten (eds.), Input Matters in SLA. Clevedon, UK: Multilingual Matters, pp. 191-206.

Bassetti, B. and Atkinson, N. (2015) 'Effects of orthographic forms on pronunciation in experienced instructed second language learners', in Applied Psycholinguistics, 36: 67-91.

doi:10.1017/S0142716414000435.

Brown, T. L. and Haynes, M. (1985) 'Literacy Background and Reading Development in a Second Language', in T. H. Carr (ed.), The development of reading skills: new directions for child development, no. 27. San Francisco: Jossey Bass.

Coleman, J. A., Galaczi, A. and Astruc, L. (2007) 'Motivation of UK school pupils towards foreign languages: a large-scale survey at key Stage 3', in Language Learning Journal, 35(2): 245-281. doi:10.1080/09571730701599252.

Coltheart, C. (2005) 'Modeling Reading: The Dual-Route Approach', in M. J. Snowling and C. Hulme (eds.), The science of reading: a handbook. Oxford: Blackwell, pp. 6-23.

Erler, L. (2003) Reading in a Foreign Language - Near-Beginner Adolescents' Experiences of French in English Secondary Schools. DPhil Thesis, Oxford University.

Erler, L. (2004) 'Near-beginner learners of French are reading at a disability level', in Francophonie, 30: 9-15.

Erler, L. and Macaro, E. (2011) 'Decoding Ability in French as a Foreign Language and Language Learning Motivation', in Modern Language Journal, 95(4): 496-518. doi:10.1111/j.1540-

4781.2011.01238.x.

Hamada, M. and Koda, K. (2008) 'Influence of first language orthographic experience on second language decoding and word learning', in Language Learning, 58(1): 1-31. doi:10.1111/j.14679922.2007.00433.x.

Hamada, M. \& Koda, K. (2010) 'The role of phonological decoding in second language word-meaning inference', in Applied Linguistics, 31(4): 513-531. doi:10.1093/applin/amp061.

IPA (International Phonetic Association) (2005) Handbook of the International Phonetic Association: A guide to the use of the International Phonetic Alphabet. Cambridge: Cambridge University Press.

Koda, K. (1989) 'Effects of L1 orthographic representation on L2 phonological coding strategies', in Journal of Psycholinguistic Research, 18(2): 201-222. doi:10.1007/BF01067782. 
Koda, K. (1990) 'The use of L1 reading strategies in L2 reading: effects of LI orthographic structures on L2 phonological recoding strategies', in Studies in Second Language Acquisition, 12: 393-410. doi: http://dx.doi.org/10.1017/S0272263100009499.

Koda, K. (1999) 'Development of L2 intraword orthographic sensitivity and decoding skills', in The Modern Language Journal, 83(1): 51-64. Retrieved from http://www.jstor.org/stable/330406.

Koda, K. (2005). 'Learning to read across writing systems: transfer, metalinguistic awareness and second-language reading development', in V. Cook \& B. Bassetti (eds.), Second language writing systems. Clevedon: Multilingual Matters, pp. 311-334.

Koda, K. (2007) 'Reading and language learning: cross-linguistic constraints on second language reading development', in Language Learning, 57, supplement 1: 1-44. doi:10.1111/00238333.101997010-i1.

Macaro, E. (2007) 'Do near-beginner learners of French have any writing startegies?' in Language Learning Journal, 35(1): 23-35. doi:10.1080/09571730701315600.

Muljani, D., Koda, K. and Moates, D. R. (1998) 'The development of word recognition in a second language', in Applied Psycholinguistics, 19: 99-113. doi:10.1017/S0142716400010602.

Pachler, N. (2002) 'Foreign language learning in England in the 21st century', in Language Learning Journal, 25: 4-7. doi:10.1080/09571730285200031.

Paribakht, T. S. and Wesche, M. (1996) 'Enhancing vocabulary acquisition through reading: a hierarchy of text-related exercise types', in The Canadian Modern Language Review, 52(2): 155-178.

Piske, T., Flege, J. E., MacKay, I. R. and Meador, D. (2002) 'The production of English vowels by fluent early and late Italian-English bilinguals', in Phonetica, 59(1): 49-71. doi:10.1159/000056205.

Plaut, D. C. (2005) 'Connectionist approaches to reading', in Margaret J. Snowling and Charles Hulme (eds.), The science of reading: a handbook. Oxford: Blackwell, pp. 24-38.

Woore, R. (2009) 'Beginners' progress in decoding L2 French: some longitudinal evidence from English Modern Foreign Languages classrooms', in Language Learning Journal, 37(1): 3-18. doi:10.1080/09571730902717398

Woore, R. (2010) 'Thinking aloud about L2 decoding: an exploration into the strategies used by beginner learners when pronouncing unfamiliar French words', in Language Learning Journal, 38(1): 3-17. doi:10.1080/09571730903545210.

Woore, R. (2011) Investigating and developing beginner learners' decoding proficiency in second language French: an evaluation of two programmes of instruction. Unpublished DPhil Thesis, University of Oxford.

Woore, R. (2013) 'Decoding, vocabulary learning and vocabulary learning strategies in beginners' L2 French'. Paper presented at EUROSLA 23, University of Amsterdam, 28-31 August 2013.

Woore, R. (2014a) 'Beginner learners' progress in decoding L2 French: transfer effects in typologically similar L1-L2 writing systems', in Writing Systems Research, 6(2): 167-189. doi:10.1080/17586801.2013.838536. 
Woore, R. (2014b) 'Developing reading and decoding in the MFL classroom', in P. Driscoll, E. Macaro \& A. Swarbrick (eds.) Debates in modern languages education. London: Routledge, pp. 81-95.

Young-Scholten, M. and Langer, M. (2015) 'The role of orthographic input in second language German: Evidence from naturalistic adult learners' production', in Applied Psycholinguistics, 36: 93114. Doi:10.1017/S0142716414000447. 